\title{
Clinical significance of interleukin (IL)-6 in cancer metastasis to bone: potential of anti-IL-6 therapies
}

\author{
This article was published in the following Dove Press journal: \\ Cancer Management and Research \\ 17 May 2011 \\ Number of times this article has been viewed
}

\author{
Ken Tawara \\ Julia T Oxford \\ Cheryl L Jorcyk \\ Department of Biological Sciences, \\ Boise State University, Boise, ID, USA
}

\begin{abstract}
Metastatic events to the bone occur frequently in numerous cancer types such as breast, prostate, lung, and renal carcinomas, melanoma, neuroblastoma, and multiple myeloma. Accumulating evidence suggests that the inflammatory cytokine interleukin (IL)-6 is frequently upregulated and is implicated in the ability of cancer cells to metastasize to bone. IL-6 is able to activate various cell signaling cascades that include the STAT (signal transducer and activator of transcription) pathway, the PI3K (phosphatidylinositol-3 kinase) pathway, and the MAPK (mitogen-activated protein kinase) pathway. Activation of these pathways may explain the ability of IL-6 to mediate various aspects of normal and pathogenic bone remodeling, inflammation, cell survival, proliferation, and pro-tumorigenic effects. This review article will discuss the role of IL-6: 1) in bone metabolism, 2) in cancer metastasis to bone, 3) in cancer prognosis, and 4) as potential therapies for metastatic bone cancer.
\end{abstract}

Keywords: interleukin-6, bone metastasis, cancer, osteoclastogenesis, osteoclast, osteoblast

\section{Introduction}

Bone homeostasis is maintained by a variety of cell types that control remodeling of the bone matrix. Two important cell types that mediate bone homeostasis are osteoblasts and osteoclasts. Osteoblasts contribute to the bone matrix by production of type I collagen, deposition of hydroxyapatite crystals into the collagen matrix, and regulation of osteoclast activity. ${ }^{1,2}$ Osteoblasts are of mesenchymal origin and differentiate from pre-osteoblasts. This process occurs via bone morphogenic proteins (BMPs) that induce runt-related transcription factor 2 (Runx2), leading to increased alkaline phosphatase activity. ${ }^{1}$ Conversely, osteoclasts resorb bone matrix ${ }^{3}$ and differentiate from the hematopoietic cell lineage upon stimulation in a differentiation process called osteoclastogenesis. Osteoclastogenesis is mediated by cytokines such as receptor activator of nuclear factor (NF)- $\kappa B$ ligand (RANKL) and macrophage-colony stimulating factor (m-CSF) (Figure 1A). ${ }^{3,4}$ RANKL, a membrane-bound ligand, and m-CSF a secreted factor, are predominantly produced by osteoblasts. ${ }^{5}$ Osteoclastogenesis is regulated primarily via RANKL and osteoblast-produced osteoprotegrin (OPG) expression, a decoy receptor to RANKL that suppresses RANKL activity. ${ }^{6}$ Osteoblasts that express RANKL have cell-to-cell contact with osteoclasts via ligand-receptor binding between RANKL and RANK (receptor activator of NF- $\kappa B$ ) expressed on osteoclasts. ${ }^{7}$ RANKL functions to promote osteoclast differentiation and activity through stimulation of various pathways including the phosphatidylinositol-3 kinase (PI3K) pathway and the mitogen activated protein kinase (MAPK) pathway. The MAPK pathway leads to the activation of c-fos, nuclear factor of activated T-cells-2 (NFAT2), and other transcription factors. ${ }^{8,9}$ 

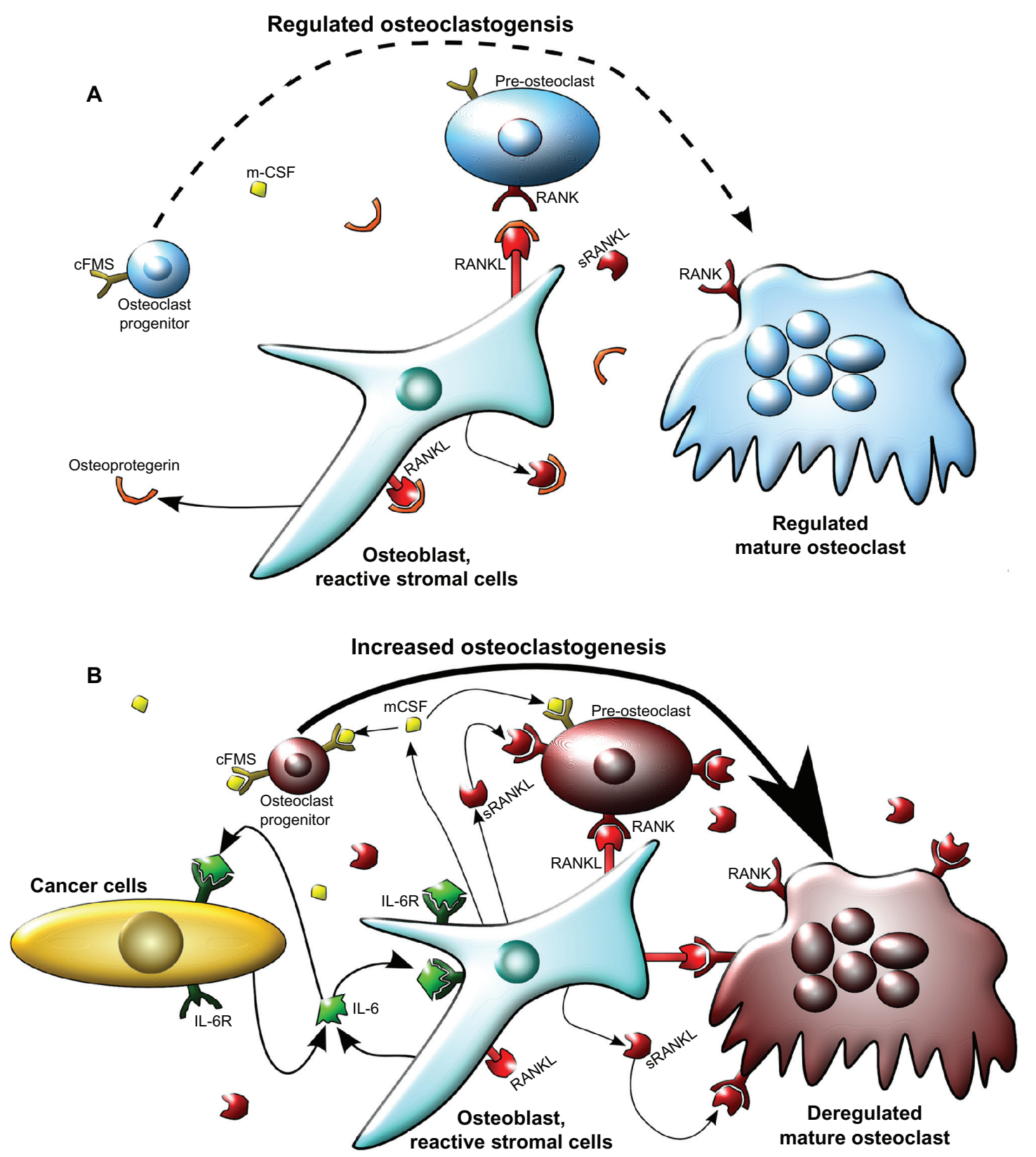

Figure I Model of osteoclastogenesis during bone homeostasis and tumor cell metastasis to bone. A) In normal bone, RANKL and m-CSF are produced primarily by osteoblasts. m-CSF binds to its receptor c-FMS, expressed on osteoclast progenitors, and RANKL binds to its receptor on pre-osteoclasts to promote osteoclastogenesis. Osteoprotegrin, also produced by osteoblasts, acts as a decoy receptor for RANKL and negatively regulates osteoclast differentiation. In this model, osteoblast and osteoclast activity are in homeostasis through careful regulation of osteoclastogenesis. B) When cancer cells metastasize to the bone, increased IL-6 may be produced by both the cancer cells and the osteoblasts, as an inflammatory response to the cancer cells. IL-6 then stimulates various types of stromal cells in the bone, which include bone marrow cells, osteoblasts, and fibroblasts in the area of the metastasis, to increase the expression of RANKL and m-CSF by osteoblasts. This IL-6-mediated increase in RANKL and $\mathrm{m}$-CSF also occurs with injury and inflammation to the bone, but unlike in cancer metastasis, it is transient. RANKL and $\mathrm{m}$-CSF then, in turn, activate the osteoclast differentiation cascade, where $\mathrm{m}$-CSF strongly stimulates early stages of osteoclast differentiation, and RANKL stimulates late stages of osteoclast differentiation, as well as osteoclast activity. Once this occurs, osteoclast activity becomes dysregulated and reduces bone integrity.

Abbreviations: c-FMS, colony stimulating factor I receptor; IL-6, interleukin 6; IL-6R, IL-6 receptor; m-CSF, macrophage-colony stimulating factor; RANKL, receptor activator of nuclear factor $K B$ ligand; sRANKL, soluble form of RANKL.

Cleavage of RANKL from the cell membrane by proteinases such as matrix metalloproteinase-7 (MMP7) yields the soluble form of RANKL (sRANKL), which has a physiological function that is still disputed, although both anti- and proosteoclastogenic effects have been reported. ${ }^{5,10-12}$
As osteoclasts differentiate in response to pro-osteoclastic factors, these cells create a segregated zone, a sealed area between the osteoclast and the bone matrix. ${ }^{9}$ Osteoclasts then release hydrogen ions into the segregated zone, solubilizing the hydroxyapatite crystals and promoting acid-activated 
proteinases such as cathepsin $\mathrm{K}$ to degrade the collagen matrix. ${ }^{9}{ }^{13}$ Osteoblasts generate new matrix to fill the vacant area. The rate at which osteoclasts differentiate and resorb bone is carefully regulated by osteoblast-produced RANKL and OPG. Other cells in the bone matrix such as osteocytes, terminally differentiated osteoblasts, are able to regulate the generation and resorption of bone matrix by affecting osteoblast and osteoclast activity. ${ }^{14}$ When osteocytes are mechanically stimulated by shock to bone resulting in dynamic fluid movement, they promote alkaline phosphatase activity in osteoblasts by cell-to-cell contact through the RANK/RANKL complex, increasing bone mineralization and turnover. ${ }^{15-17}$ In this manner, damaged sections of the bone are removed and are replaced with new bone matrix by osteoblasts.

In normal bone, homeostasis is maintained and bone integrity is preserved by a continuous cycle of bone renewal. However, when cancer cells metastasize to the bone, the balanced and complex interplay of the cells is disrupted, leading to a pathologic condition that compromises bone integrity. One of the many characteristics that bone-homing cancer cells have in common is that most of them release copious levels of interleukin (IL)-6, which helps in facilitating bone invasion and growth of metastatic lesions. ${ }^{18-20}$ In this review article, the role of IL- 6 in facilitating bone metastasis and approaches to measure serum IL-6 to predict progression of metastatic disease will be discussed. Additionally, new therapies targeting IL- 6 and their potential efficacy in preventing bone metastasis will be reviewed.

\section{Frequency, consequences, and mechanisms of cancer cell metastases to bone}

Various types of cancers metastasize to the bone, including breast, prostate, lung, thyroid, kidney, multiple myeloma, melanoma, and neuroblastoma. ${ }^{21-25}$ Usually the bone is only compromised at the site of metastasis, and not all types of bone metastases affect the bone in the same way. For example, breast cancer predominantly causes osteolytic lesions, resulting in an upregulation of osteoclast activity and subsequent decreased bone density and integrity that may lead to fractures. ${ }^{22,26}$ Conversely, prostate cancer results in primarily osteoblastic lesions that are caused by cytokine-induced upregulation of osteoblast activity and subsequent increased bone density. ${ }^{26}$ This type of bone metastasis causes thickening of the bone, resulting in the possibility of nerve compression, vertebral fusion, and spinal cord compression depending on the location of the metastases. In contrast to what is found in normal bone where collagen fibers are highly organized and tightly packed, bone created by osteoblastic lesions contains disorganized and fragile collagen fibrils. ${ }^{27}$ This leads to a high degree of bone brittleness, increase in potential fractures, and pain as the normal bone is replaced by abnormal bone created by the osteoblastic lesions. A subset of prostate cancers may also cause osteolytic lesions due to the expression of different cytokines that promote osteoclast activity rather than osteoblast activity. ${ }^{28}$ Multiple myeloma causes only osteolytic lesions. Other cancers, including lung, kidney, and thyroid carcinomas, result in primarily osteolytic lesions, but osteoblastic lesions occur occasionally. ${ }^{26,29}$ Metastasis of the primary tumor to the bone occurs in about $60 \%-75 \%$ of patients with metastatic breast cancer, prostate cancer, neuroblastoma, or multiple myeloma. ${ }^{21-23,30}$ Metastases to the bone from other cancers such as lung, kidney, and thyroid only occur in $30 \%-50 \%$ of patients with metastases. ${ }^{24}$

The molecular mechanisms that determine when a cancer cell will metastasize to bone are not completely understood. Recent evidence shows that the CXC chemokine receptor 4/ chemokine (C-X-C motif) ligand 12 CXCR4/CXCL12 axis may play a role in this metastatic process. Studies have demonstrated that cancer cells are attracted to the bone marrow due to the relatively high levels of CXCL12 expressed by osteoblasts, which acts as an attractant for the CXCR4 ligandpositive cancer cells. ${ }^{31}$ Numerous studies have demonstrated that bone metastatic cancer cells from the breast, prostate, and myeloma overexpress the CXCR4 ligand, which promotes homing and metastasis to the bone and other organs. ${ }^{32-35}$ Inflammatory cytokines, such as IL-6, increase CXCR4 expression in breast cancer cells, specifically in a signal transducer and activator of transcription 3 (STAT3), and c-Jun-dependent manner. ${ }^{36}$ Given these findings, therapeutics designed to block the CXCR4/CXCL12 axis are being evaluated in the prevention of bone metastases. ${ }^{37}$

Once cancer cells colonize in the bone, they have to adapt to the challenges of cell survival and growth in a foreign tissue environment. The bone is a reservoir of a complex mixture of growth factors ${ }^{38}$ that are released as the bone is degraded by metastatic lesions. The mixture of these growth factors include transforming growth factor (TGF)- $\beta$, insulin like growth factor (IGF)-1, insulin-like growth factor (IGF)-2, platelet derived growth factor (PDGF), bone morphogenic proteins (BMP), fibroblast growth factors (FGF), and other factors that significantly improve tumor cell survival and growth. ${ }^{39}$ These factors can promote the expression of prosurvival signals such as B-cell lymphoma 2 (Bcl-2) and AKT, which inhibit apoptosis in the cancer cells. In addition, these 
factors can also support further osteoclast differentiation and activity, leading to a vicious positive feedback loop (the vicious tumor-bone cycle) where additional growth factors are released, stimulating increased cancer cell growth and accelerated bone destruction. This accelerated bone destruction can lead to rapid loss of bone integrity in cancer patients causing fractures, pain, and loss of mobility.

\section{IL-6, other cytokines, and growth factors in the bone microenvironment}

IL-6 is a major pleiotropic, pro-inflammatory cytokine which plays a role in immune response, hematopoiesis, cell differentiation, wound repair, and bone remodeling. ${ }^{40,41}$ Inflammation in the bone caused by injury or disease increases expression of IL- 6 by reactive stromal cells of the bone and infiltrating monocytes and macrophages, promoting bone remodeling evidenced by higher osteoclast activity. ${ }^{42}$ The reactive stromal cells for bone metastases are generally the mesenchymal stem cells in the bone marrow as well as the fibroblasts, osteoblasts, and osteocytes in the region. IL-6 production is directly stimulated by prostaglandin E2 (PGE2) and TGF- $\beta$, while IL-1 $\beta$ and lipopolysaccharides indirectly stimulate IL-6 production via NF- $\kappa$ B activation (Figure 2). ${ }^{43-48}$ IL-6 binds to its heterotrimeric receptor, consisting of two gp130 subunits and an IL-6 receptor subunit, on target cells and activates the STAT, MAPK, and PI3K pathways. ${ }^{49-52}$ IL-6 signaling through the Janus kinase (JAK)/ STAT3 pathways lead to expression of RANKL from osteoblast/stromal cells, causing direct stimulation of osteoclast differentiation and activity and resulting in bone destruction (Figure 3). ${ }^{53,54}$ Studies using IL-6 knockout mice have demonstrated that IL-6 is necessary for upregulating osteoclast activity and bone resorption in vivo. IL-6 knockout mice were shown to be protected from increased osteoclast activity and subsequent bone degradation when their bones were injected with the arthritis-inducing antigen heat-killed Mycobacterium tuberculosis. ${ }^{55}$ IL-6 knockout bones that received antigen injections had less RANKL and IL-17 expression as well as reduced osteolysis and cartilage destruction near the site of injection compared with wild-type mice. IL-17 is a proinflammatory and pro-osteoclastogenic cytokine implicated in arthritis and tumorigenesis that is produced in $\mathrm{CD} 4^{+}$helper and tumor infiltrating T-cells when activated by IL-6. ${ }^{56,57}$ Additional mouse studies have demonstrated that inhibition of IL-6 activity, with an IL-6 receptor (IL-6R) antagonist that inhibits downstream receptor signaling, reduces bone resorption. ${ }^{58}$ These results suggest that IL-6 plays a major role in the upregulation of additional pro-osteoclastic factors essential for osteoclast activity.

Deregulation of IL-6 expression is implicated in disorders of bone homeostasis such as osteoporosis and osteopetrosis. Sex hormones such as $17-\beta$-estradiol and testosterone have been shown to regulate IL-6 levels in the bone microenvironment. 17- $\beta$-estradiol is known for its bone-preserving effects, which is supported by the fact that post-menopausal women experience a decrease in bone mineralization and density that may lead to osteoporosis. ${ }^{59}$ A recent study shows that $17-\beta$-estradiol reduces both IL- 6 and IL- 8 production by monocytes and multiple myeloma cells through a mechanism

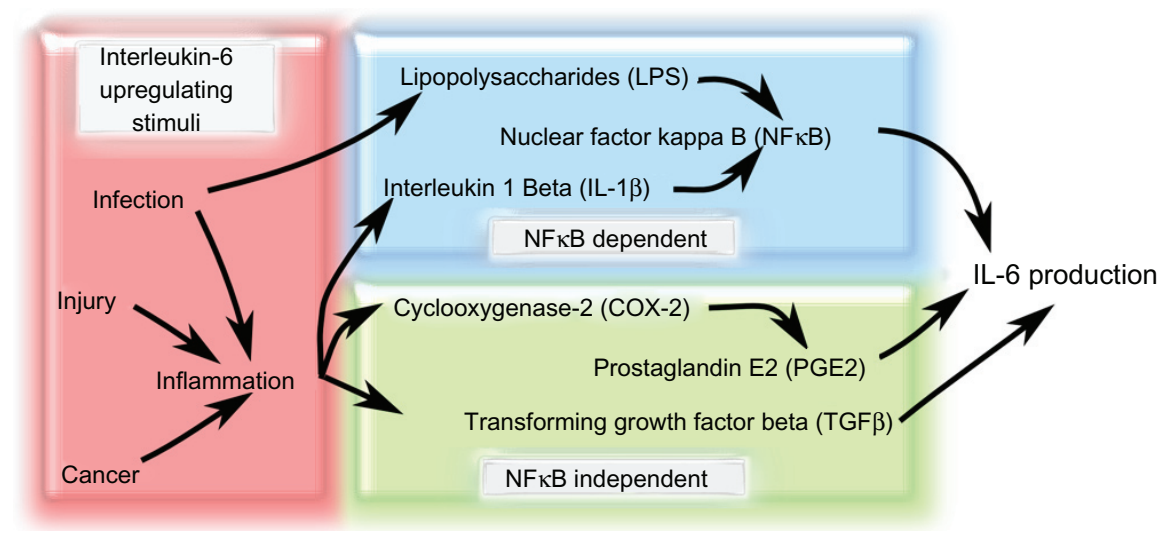

Figure 2 Factors that increase IL-6 production in response to various stimuli. Increased IL-6 production is associated with stimuli such as infection and inflammation. Infection, injury, and cancer can all stimulate inflammation that can lead to the increase of IL-6-modulating factors such as IL-I $\beta$, COX-2, PGE2, and TGF- $\beta$. Infection can also promote LPS secretion from bacteria, which increases NF- $\kappa B$-dependent IL- 6 levels. There are two main IL- 6 production pathways: NF- $K B-d e p e n d e n t$ and NF- $\kappa B$ independent. NF- $\kappa B$-independent pathways upregulate IL-6 secretion via TGF- $\beta$ or PGE2, which is produced downstream of COX-2 activation. In the NF- $\kappa B-$ dependent pathway, LPS or IL-I $\beta$ stimulate NF- $\kappa B$ activity that causes an increase in IL-6 production.

Abbreviations: COX-2, cyclooxygenase 2; IL-I $\beta$, interleukin I $\beta$; IL-6, interleukin 6; LPS, lipopolysaccharide; NF- $\kappa B$, nuclear factor $\kappa B$; PGE2, prostaglandin E2; TGF- $\beta$, transforming growth factor $\beta$. 


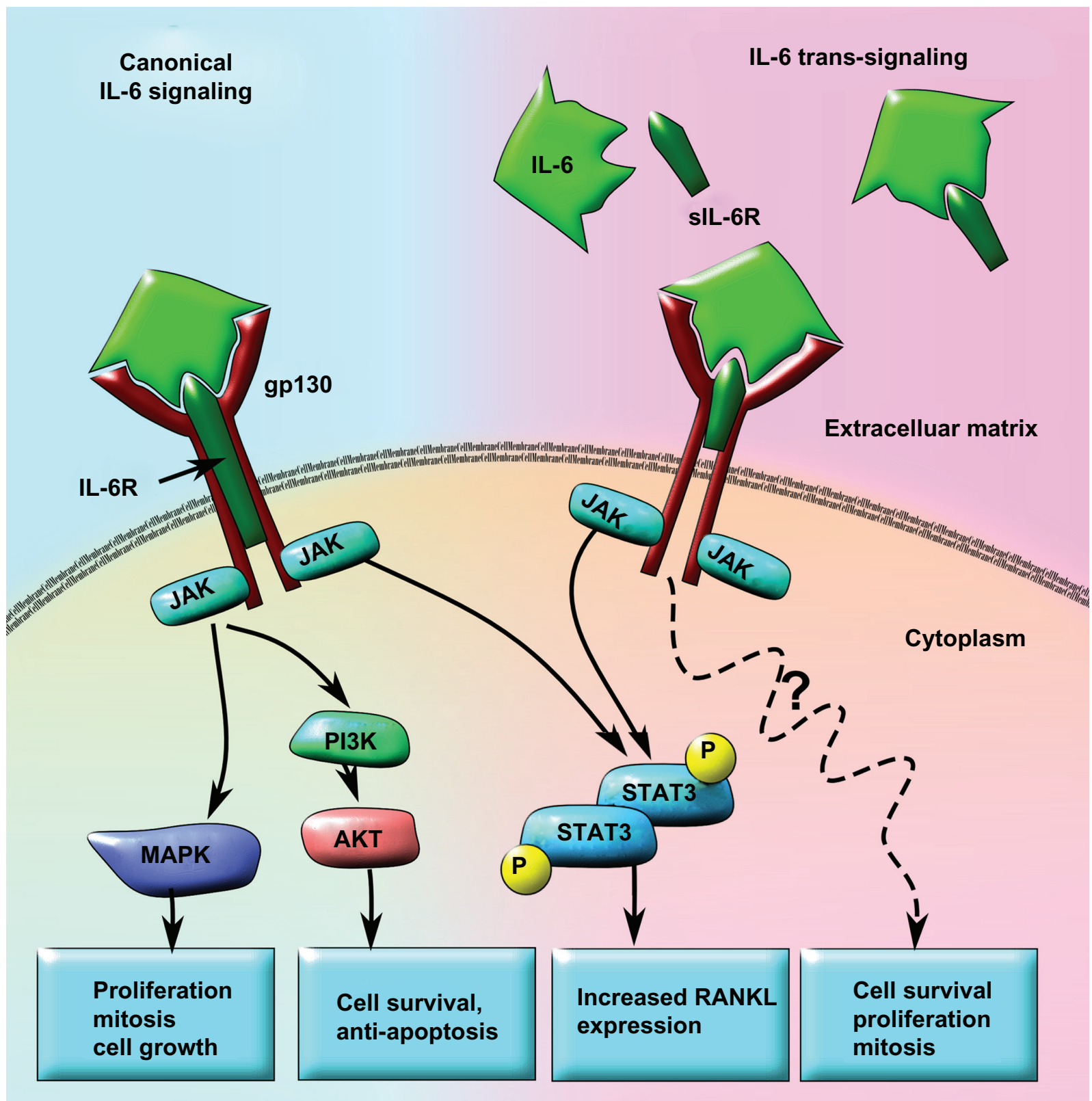

Figure 3 Model of canonical IL-6 signaling versus IL-6 trans-signaling in tumor progression and metastases. In the canonical IL-6 signaling pathway, the IL-6 receptor subunit is membrane bound and forms a heterotrimer with two gpl30 subunits. When IL-6 binds to the receptor, STAT3 is activated in a JAK-dependent manner that leads to increased RANKL expression. IL-6 may also activate AKT via increased JAK-dependent PI3K activity and result in cell survival and anti-apoptosis signaling. Concomitantly, increased MAPK activity downstream of JAK activation can lead to upregulated cell growth, proliferation, and mitosis. In the IL-6 trans-signaling pathway, IL-6 first binds to the truncated sIL6R. The IL-6/sIL6R complex then binds to the membrane-bound gpI 30 dimer to form an IL-6 trans-signaling complex. Due to the fact that the sIL-6R lacks a membrane signaling domain, there appears to be significant differences in the intracellular signaling pathways. While IL-6 trans-signaling also leads to phosphorylation and activation of STAT3, increased cell survival, proliferation, and mitosis occurs in an AKT-and MAPK-independent manner. The exact mechanisms for IL-6 trans-signaling leading to increased cell survival, proliferation, and mitosis are not yet known.

Abbreviations: IL-6, interleukin 6; JAK, Janus kinase; MAPK, mitogen-activated protein kinase; PI3K, phosphatidylinositol 3-kinase; RANKL, receptor activator of nuclear factor $\kappa B$ ligand; sIL6R, soluble IL-6 receptor; STAT3, signal transducer and activator of transcription 3.

that is not yet fully understood. ${ }^{60,61}$ The chemokine IL-8 is also a pro-inflammatory molecule, which like IL-6, can increase inflammation in the bone and cause excessive bone resorption by upregulating the transcription factor $\mathrm{NF}-\kappa \mathrm{B} .{ }^{62,63}$ In turn, increased NF- $\kappa \mathrm{B}$ activity stimulates IL-6 expression and secretion into the extracellular matrix. ${ }^{64}$ Studies have shown that the binding of $17-\beta$-estradiol to the estrogen receptor inhibits $\mathrm{NF}-\kappa \mathrm{B}$ transcriptional activity by preventing inhibitor of NF- $\kappa \mathrm{B}$ alpha $(\mathrm{I} \kappa \mathrm{B} \alpha)$ degradation, leading to decreased IL-6 expression. ${ }^{60,65} \mathrm{I} \kappa \mathrm{B} \alpha$ is normally constitutively expressed and bound to NF- $\kappa B$, thus preventing the translocation of the transcription factor into the nucleus and initiation of the transcription of NF- $\kappa B$-related genes. ${ }^{66} 17-\beta$-estradiol has also been shown to suppress 
IL-6 activity by inhibiting STAT3 through upregulation of protein inhibitor of activated STAT3 (PIAS3) ${ }^{67}$ In addition, testosterone decreases IL- 6 expression by inhibiting NF- $\kappa \mathrm{B}$ activity in osteoblasts via the hypothalamic-pituitary-adrenal axis, normally a potent stimulator of IL- 6 production. Both of these result in testosterone-mediated bone-preserving effects. ${ }^{68-70}$ Therapies that involve suppression of testosterone and 17- $\beta$-estradiol are effective against androgen-dependent prostate and breast cancer respectively; however, bone density decreases significantly with these therapies leading to an increased chance of developing osteoporosis. ${ }^{71}$

\section{IL-6 production by cancer cells and stromal cells in the bone microenvironment facilitates invasion and metastasis}

IL-6 produced by cancer cells initiates a variety of downstream signaling cascades that can lead to bone destruction (Figure 1B). Many cancer cell types that metastasize to the bone endogenously produce and secrete high levels of IL-6. On the other hand, other cancer cell types stimulate the surrounding stromal cells to release copious amounts of this cytokine. Some cancer cell types such as IL-6-dependent multiple myeloma cells do not express IL-6 and rely on the bone microenvironment's reactive stromal cells to produce IL-6 in response to the presence of the tumor cells. ${ }^{72}$ This stroma-dependent increase of IL-6 in the extracellular matrix may be specific to the microenvironment of the metastasis. For example, injection of Walker (W256) mouse mammary cancer cells and MatLyLu (MLL) mouse prostate cancerlike cells into mice has been shown to differentially express IL-6 depending on the location. ${ }^{73}$ Specifically, local injection of W256 and MLL cells into the bone causes upregulation of IL-6, macrophage colony stimulating factor (m-CSF), RANKL, and Dickkopf-related protein 1 (DKK1) in the bone stromal cells. DKK1 is a member of the dickkopf family of factors that has been shown to be elevated in the bone marrow of patients with breast cancer bone metastases. ${ }^{74}$ However, when these cells metastasized to nonosseous organs, there was little to no expression of IL-6, m-CSF, RANKL, or DKK1, indicating that some cancer cells stimulate surrounding cells to release pro-osteoclastic factors only in the bone microenvironment. ${ }^{73,75}$

It has been proposed that cancer cells induce an inflammatory response in osteoblasts which may lead to the stimulation of osteoclast differentiation and activity. ${ }^{76,77}$ The inflammatory response of osteoblasts in response to cancer cell-conditioned medium in vitro has been shown to cause an upregulation of PGE2, which induces IL-6 and activates osteoclasts via RANKL and PTHrP production. ${ }^{18,74,75}$ This effect was seen in breast cancer cells, oral squamous carcinoma cell lines, and in neuroblastoma cells. ${ }^{18,75,76}$ The induction of the inflammatory response to the cancer cellconditioned medium may be due to NFKB activation via an IL-6-independent mechanism within the osteoblasts. ${ }^{77}$ Suppression of NFKB activity with methylseleninic acid reduced cytokine production by osteoblasts in response to cancer cell-conditioned medium, which may translate to reduced bone destruction in vivo.

IL-6 has been demonstrated to increase RANKL expression from osteoblasts and thus stimulate osteoclastogenesis. However inhibitors of RANKL fail to suppress IL-6-mediated osteoclastogenesis and bone resorption. ${ }^{78,79}$ This suggests that IL-6 has potential redundant pathways that upregulate bone destruction and could interfere with the efficacy of targeted therapies against RANKL such as denosumab, a humanized monoclonal antibody against RANKL. ${ }^{80}$ RANKL-independent pathways could mediate IL-6 induced osteoclastogenesis. For instance, cancer induced inflammation leads to the stimulation of NF- $\mathrm{KB}$ activity, which initiates IL-6 production (Figure 2). NF- $\kappa \mathrm{B}$ activity is also able to stimulate cyclooxygenase (COX)-2 activity, which would result in the production of PGE2, stimulating more IL-6 release ${ }^{81}$ High levels of PGE2 have been shown to promote potent, pro-osteoclastic factors. ${ }^{82}$ IL-6 may also be inducing other pro-osteoclastic factors that functions independently from RANKL such as IL-1 $\beta .^{83} \mathrm{IL}-1 \beta$ has also been shown to increase NF- $\kappa B$ activity ${ }^{84}$ that could result in a feedback loop that further increases IL-6.

\section{IL-6 and its soluble receptor as a prognostic factor for cancers that metastasize to bone}

Predicting disease outcomes in cancer patients with metastasis to bone is difficult due to the inherent high level of tumor cell heterogeneity within a specific type of cancer. Current attempts at general prognostics are based mostly on tumor grading, staging, and invasive characteristics derived from histological and other types of physical analysis of biopsies. ${ }^{85}$ Specific, factor-based categorization of cancer is limited to a handful of well characterized receptor and antigenic tests. For example, prostate specific antigen (PSA) has long been used as a prognostic factor to estimate progression of prostate cancer ${ }^{86}$ Immuno-assays are performed to detect receptors for estrogen (ER), progesterone (PR), and human 
epidermal growth factor receptor 2 (Her2/neu) to aid in directing treatment strategies for breast cancer. ${ }^{87}$ Improving prediction accuracy by using more prognostic factors can hasten the detection of any changes in the progression of the disease.

Recently, interest in using serum IL-6 as a specific prognostic factor for prostate cancer and breast cancer has risen. ${ }^{88-90}$ Current research demonstrates that serum IL-6 levels are significantly increased in many cancer patients with invasive prostate cancer compared with benign prostatic hyperplasia (BPH). ${ }^{91}$ It has been shown that higher levels of serum IL-6 in patients with castration-resistant prostate cancer correlates to shortened survival times. ${ }^{92}$ Serum IL-6 is also elevated in prostate and breast cancer patients with distal metastases compared with patients without metastases, ${ }^{92,93}$ and higher serum IL-6 levels have been associated with lower patient survival rates in metastatic breast and prostate cancer. ${ }^{94}$ The spread of breast cancer cells into the local lymphatic system is also significantly correlated with increased IL-6 levels. ${ }^{93}$ Other studies have supported these findings and have shown that IL-6 correlates with the extent and size of prostate cancer bone metastases; specifically, the larger and more compromised the bone was, the higher the level of serum IL-6. ${ }^{95,96}$ Furthermore, significant elevation of IL-6 levels in the serum have been seen in prostate cancer patients who have experienced a relapse, where IL-6 levels positively correlate with cachexia. ${ }^{90,97}$ Additionally, IL-6 levels have been shown to correlate with measures of morbidity and poor patient health. ${ }^{98}$ In one case study, a sharp increase in serum IL-6 was detected in terminally ill cancer patients who were experiencing extreme cachexia. ${ }^{99}$

A comprehensive study involving patients with metastatic gastric cancer, which can also metastasize to the bone, ${ }^{100,101}$ demonstrated a significant correlation between serum IL-6 levels and the extent of gastric cancer progression. ${ }^{102}$ Specifically, IL-6 levels correlated with tumor grade and the extent of invasion into the gastric organ as well as lymphatic and hepatic systems. Long-term survival rates were much higher with patients that had low levels of serum IL-6, and post-surgical probability of metastasis was higher in patients with high serum IL-6. ${ }^{102}$ The use of serum IL-6 levels for prognosis in a clinical setting is limited by gaps in the current understanding of mechanisms by which IL-6 specifically mediates the progression of metastatic disease as well as a lack of large clinical trials to assess baseline and range of fluctuation of serum IL-6 levels.

In addition to serum IL-6 levels, the concentration of soluble receptor to IL-6 (sIL-6R) in the serum may also help predict the aggressiveness of cancer metastasis and the level of bone destruction. Even in the absence of cancer, high levels of serum concentration of sIL-6R can predict the rate and level of osteolysis in patients with hyperparathyroidism. ${ }^{103}$ High levels of sIL-6R in the serum have also been associated with increased generalized inflammation, rheumatoid arthritis, inflammatory bowel disease, asthma, and inflammationassociated colorectal cancer. ${ }^{104}$ sIL-6R enables a process called IL-6 trans-signaling, where cells that do not possess IL-6 receptor, or have low levels of it, can respond to IL-6 (Figure 3). This occurs through an unclear mechanism by incorporating the sIL-6 receptor into the gp130 receptor dimer on the cells, forming a IL-6 receptor heterotrimer and enabling the cells to respond to IL- $6 .{ }^{105}$ Interest in IL-6 trans-signaling has increased in the past several years as new research show that sIL-6R is produced by various cancer cells, and the serum concentration is associated with decreased survival and increased aggressiveness of metastases in breast, prostate, and colorectal cancers. ${ }^{95,106,107}$ Some data suggest that IL-6 trans-signaling causes various effects that promote cancer metastases including, increased detachment, proliferation, and migration through a pathway that is independent of STAT1, STAT3, or MAPK. ${ }^{108}$ This suggests that IL-6 trans-signaling is distinct from the canonical IL-6 signaling pathway and could be due to the lack of the membrane signaling domain on the sIL-6 receptor subunit (Figure 3). However, IL-6 trans-signaling does cause increased RANKL expression in synovial fibroblasts through a STAT3-dependent manner, ${ }^{53}$ which suggests that trans-signaling may use some of the canonical IL-6 pathway to exert its effects. Although there is a convincing amount of evidence to suggest that higher serum sIL-6R levels may be associated with a worse cancer prognosis, little is known about the specifics of the IL- 6 trans-signaling pathway, and more studies need to be done before assessing whether sIL-6R is a therapeutic target.

\section{Serum IL-6 levels may predict response to cancer therapy}

It is critical to determine throughout a patient's treatment whether the current therapy plan should be maintained or whether new therapies need to be initiated. Changes in serum IL-6 levels in patients undergoing chemotherapies or targeted therapeutics may act as a biomarker that can predict whether a patient is responding or not. In one clinical study, combination therapy using docetaxel and zoledronic acid, a bisphosphonate that inhibits osteoclastic activity, was administered to prostate cancer patients with bone metastases. ${ }^{109}$ 
Patients that responded to the therapy had a 35\% decrease in overall serum IL-6 levels, while patients that did not respond had a 76\% increase in serum IL-6 levels. ${ }^{109}$ A confounding variable in this finding is that some of the increase in serum IL-6 may be due to a stress response to the chemotherapeutic agents themselves, and the high levels of IL-6 may actually confer drug resistance. ${ }^{110}$ However, IL-6 has also been correlated to C-reactive protein (CRP) levels in the serum, and reduction in CRP levels alone may indicate positive biologic effects of chemotherapeutics indicated by a reduction in serum IL-6. ${ }^{111,112}$ Although there is a dearth of clinical studies using IL-6 as a predictive biomarker of therapeutic response, initial studies support the concept that changes in serum cytokine levels such as IL-6 are worthy of more investigation.

\section{IL-6 promotes chemotherapy resistance}

Chemotherapeutics traditionally have been and are currently, a mainstay in therapies against metastatic disease. However, resistance to chemotherapeutics is common, and the mechanisms mediating resistance have been difficult to determine. Recent experimental results suggest that chemotherapy resistance is mediated through a relatively heterogeneous set of mechanisms, including downregulation of apoptotic signals, increased drug clearing and deactivation from cancer cells, multidrug resistance gene mutations, and stimulation of cell survival pathways via gene amplification. ${ }^{113-115}$

A substantial amount of chemotherapy resistance research presently focuses on upstream mediators of cell survival. In the bone microenvironment, high concentrations of IL-6 have recently been shown to confer resistance to apoptosis in breast and prostate cancer cells as well as neuroblastoma cells. ${ }^{18,116,117}$ Specifically, prostate cancer cell activity of NF- $\kappa \mathrm{B}$ has been shown to cause high IL-6 production, which promotes docetaxel resistance in prostate tumors and associated bone metastases by upregulating the pro-survival AKT pathway in an IL-6-dependent manner (Figure 3). ${ }^{49}$ Additionally, resistance to paclitaxel is observed in breast cancer patients whose metastatic lesions show high levels of IL- $6 .{ }^{115}$ This high IL-6 production could itself be a function of the cancer cell's response to chemotherapeutics. One particular study presented evidence that paclitaxel induced expression of IL-6 in cervical cancer cells via the c-Jun N-terminal kinase (JNK) signaling pathway. ${ }^{110}$ More studies need to be conducted to assess the full role of IL-6 in conferring chemotherapeutic resistance, but these preliminary studies may support a rationale for using combination therapy of IL-6 inhibitors along with classical chemotherapeutic agents.

\section{IL-6 as a target for therapy}

Currently, the only kinds of therapies that can treat bone metastases are supportive therapies using 1) bisphosphonates to reduce osteolytic burden, 2) radiotherapy and analgesics to alleviate pain, and 3) surgical intervention to reinforce weak bones. ${ }^{24,118,119}$ The humanized monoclonal antibody to the IL-6 receptor, tocilizumab (Actemra ${ }^{\circledR}$ ) was approved by the United States Food and Drug Administration (FDA) on January 11, 2010 and was previously approved in Japan and the European Medicines Agency (EMEA) in 2008 (Table 1). ${ }^{120}$ Although tocilizumab is approved only for rheumatoid arthritis (RA) in the United States and Europe as well as Castleman's disease in Japan, recent studies have shown that tocilizumab is also effective as an antitumor agent against U87MG glioma cells. Tocilizumab exerts an inhibitory effect on the JAK/STAT3 pathway by preventing IL-6 from binding to its receptor, thereby inhibiting IL-6 signaling. ${ }^{121}$ Similar antitumor effects were seen with S6B45 multiple myeloma cells where a modified version of tocilizumab significantly inhibited the proliferation of these cells in vitro. ${ }^{122}$ Tocilizumab has also been effective in blocking cartilage and bone destruction in IL-6-mediated autoimmune diseases such as synovitis and RA, where the mechanism of bone destruction is similar to that of bone metastases and high, local IL-6 levels were reported. ${ }^{123}$ Thus, tocilizumab may be effective as part of a combination therapy with bisphosphonates to control cancer cell-mediated destruction of the bone. However, there is no public data that exists for the efficacy of tocilizumab in inhibiting the progression of bone metastases. Other inhibitors of IL-6 activity for the treatment of various autoimmune diseases such as lupus, RA, Crohn's disease, and Castleman's disease are being developed or are undergoing FDA approval.

Another anti-IL-6 drug that is being developed for bone metastatic prostate and renal carcinomas and multiple myeloma is (Centocor's) CNTO-328 (Siltuximab). ${ }^{124}$ This chimeric, monoclonal antibody to IL- $6^{120,125}$ recently completed initial clinical trials for prostate cancer, kidney cancer, and renal cell carcinoma with mixed results. Some preliminary results from the completed trials indicate minimal side effects with the inhibitor; however, there was a general lack of correlation with IL-6 inhibition and reduction in tumor growth. ${ }^{125,126}$ The lack of tumor inhibition may be due to the nature of the trial that attempted to ascertain the safety profile of the drug, thereby leading to the use of a lower dose than may be effective. However, new clinical trials with dose escalation are planned. On the other hand, clinical trials on relapsed and refractory multiple myeloma 
Table I Targeted therapies for IL-6

\begin{tabular}{|c|c|c|c|c|}
\hline FDA approval status & Drug manufacturer & Drug name & Drug type & Reference \\
\hline \multicolumn{5}{|l|}{ Approved drugs } \\
\hline $\begin{array}{l}\text { Approved for rheumatoid } \\
\text { arthritis }\end{array}$ & Roche and Chugai & Tocilizumab & $\begin{array}{l}\text { Monoclonal humanized } \\
\text { antibody to IL-6 receptor }\end{array}$ & $\begin{array}{l}\text { Melton } L \text { et al }{ }^{120} \\
\text { Kudo } M \text { et al }\end{array}$ \\
\hline \multicolumn{5}{|l|}{ Promising drugs in trials } \\
\hline $\begin{array}{l}\text { Phase } 2 \text { trials prostate cancer, } \\
\text { multiple myeloma }\end{array}$ & Centocor & CNTO-328 & $\begin{array}{l}\text { Monoclonal chimeric } \\
\text { antibody to IL-6 }\end{array}$ & $\begin{array}{l}\text { Melton } L \text { et al }{ }^{120} \\
\text { Zaki MH et al }\end{array}$ \\
\hline $\begin{array}{l}\text { Phase I trials completed and } \\
\text { Phase } 2 \text { trials pending }\end{array}$ & Avida, purchased by Amgen & C 326 or AMG-220 & Avimers & $\begin{array}{l}\text { Silverman et al }\left.\right|^{133} \\
\text { Sheridan } C^{132}\end{array}$ \\
\hline
\end{tabular}

is still ongoing. Preliminary results from a Phase 2 trial on these patients demonstrate positive results with manageable side effects and good safety profile. ${ }^{127}$ This is supported by a study showing that siltuximab can inhibit prostate cancer cell growth in vitro and improve survival by reducing the level of cachexia in an animal model of prostate cancer. ${ }^{128}$ In addition, siltuximab has been shown in mice to inhibit the conversion of androgen-dependent prostate cancer into a more aggressive, bone metastatic, and difficult to treat androgen-independent prostate cancer. ${ }^{129}$ Treatment with siltuximab also decreased serum CRP levels, which correlated to improved outcome in treatment-resistant prostate cancer. ${ }^{112}$ Other recent data indicate that STAT3 and MAPK activity is suppressed in patients taking siltuximab, which may inhibit IL-6 mediated drug resistance. ${ }^{130}$ However, in a separate Phase 2 clinical trial involving castration-resistant prostate cancer where the disease had progressed beyond docetaxel therapy, siltuximab had a minimal clinical effect, despite positive biological IL-6 inhibition. ${ }^{131}$ New clinical trials using a combination of siltuximab and chemotherapeutics such as docetaxel are underway. ${ }^{131}$

The use of antibodies for therapeutically inhibiting cytokines such as IL-6 may soon be replaced by utilizing small protein, nonantibody-based inhibitors called avimers. Avimers may surpass monoclonal antibodies in efficacy and potency, while reducing cost. Because these proteins lack immunoglobulin domains, they are much less immunoreactive, and their smaller size $(\sim 4 \mathrm{kDa})$ allows tighter interactions between the avimer and their target cytokine or receptor. ${ }^{132,133}$ In addition, due to their reduced immunoreactive nature, they should theoretically reduce occurrences of serious side effects such as acute allergic reactions, which currently are a common problem with antibody therapeutics. Because of the promising features of this type of biological therapeutic, many pharmaceutical companies are pursuing the development of drugs based on nonantibody protein compounds, but the majority of these compounds are still in preclinical or Phase 1 trials.
Avida recently developed an avimer against IL-6 called C326 or AMG-220. ${ }^{134}$ Their studies show that this avimer has superior stability and drug longevity compared with antibody-based inhibitors, ${ }^{73}$ resulting in an increase in both the half-life and the shelf-life of the drug. Avida published results demonstrating that their avimer against IL-6 has an $\mathrm{IC}_{50}$ in the picomolar range leading to much smaller doses, and as it can be produced in Escherichia coli, the cost is reduced. ${ }^{133}$ AMG-220 is also being developed for Castleman's disease, an autoimmune disorder that is characterized by high levels of serum IL-6 which is thought to cause the hyper-proliferation of B-cells, leading to high fevers, joint pain, weight loss, and anemia. ${ }^{135}$ Currently, a Phase 1 trial for Crohn's disease is also in progress and is recruiting volunteers with stable disease and generally good health. ${ }^{133,136,137}$

Although not all IL-6 inhibitors currently being developed or on the market are designed for cancer, IL-6 inhibitors, in principle, should work similarly for all diseases where IL-6 is deregulated. Therefore, IL-6 inhibitors should effectively inhibit IL-6-dependent cancers by reducing metastases to the bone and bone destruction. Availability of IL-6 inhibitors for the treatment of various cancers and bone metastases should improve as new uses of the inhibitors are approved by the FDA.

\section{Conclusion}

Recent research and publications have demonstrated that IL-6 is one of the major factors upregulating and modulating cancer-mediated bone destruction. The information presented in this review illustrates the potential for IL- 6 as a prognostic factor. In addition, fluctuations in serum IL-6 levels could help direct additional treatment strategies in the future, but clinical studies are needed to assess that potential. There is also evidence from in vitro, in vivo, and preliminary clinical trials to suggest that specific anti-IL-6 therapies may improve cancer survival rates and reduce metastatic burden in some types of cancers. However, additional studies and appropriate clinical trials need to be done to fully ascertain the effectiveness of anti-IL-6 therapies in cancer patients. 


\section{Disclosure}

The authors declare that they have no conflict of interest.

\section{References}

1. Jensen ED, Gopalakrishnan R, Westendorf JJ. Regulation of gene expression in osteoblasts. Biofactors. 2010;36(1):25-32.

2. Orimo $\mathrm{H}$. The mechanism of mineralization and the role of alkaline phosphatase in health and disease. J Nippon Med Sch. 2010;77(1):4-12.

3. Teitelbaum SL. Bone resorption by osteoclasts. Science. 2000; 289(5484):1504-1508.

4. Ducy P, Schinke T, Karsenty G. The osteoblast: a sophisticated fibroblast under central surveillance. Science. 2000;289(5484):1501-1504.

5. Nakashima T, Kobayashi Y, Yamasaki S, et al. Protein expression and functional difference of membrane-bound and soluble receptor activator of NF-kappaB ligand: modulation of the expression by osteotropic factors and cytokines. Biochem Biophys Res Commun. 2000; 275(3):768-775.

6. Kearns AE, Khosla S, Kostenuik PJ. Receptor activator of nuclear factor kappaB ligand and osteoprotegerin regulation of bone remodeling in health and disease. Endocr Rev. 2008;29(2):155-192.

7. Martin TJ, Ng KW. Mechanisms by which cells of the osteoblast lineage control osteoclast formation and activity. J Cell Biochem. 1994;56(3): 357-366.

8. Takayanagi H, Kim S, Koga T, et al. Induction and activation of the transcription factor NFATc1 (NFAT2) integrate RANKL signaling in terminal differentiation of osteoclasts. Developmental Cell. 2002; 3(6):889-901.

9. Boyle WJ, Simonet WS, Lacey DL. Osteoclast differentiation and activation. Nature. 2003;423(6937):337-342.

10. Hikita A, Yana I, Wakeyama H, et al. Negative regulation of osteoclastogenesis by ectodomain shedding of receptor activator of NF- $\mathrm{\kappa B}$ ligand. J Biol Chem. 2006;281(48):36846-36855.

11. Lynch CC, Hikosaka A, Acuff HB, et al. MMP-7 promotes prostate cancer-induced osteolysis via the solubilization of RANKL. Cancer Cell. 2005;7(5):485-496.

12. Sasano T, Suzuki O, Kanzaki H, et al. Is RANKL shedding involved in immune cell-mediated osteoclastogenesis? Interface Oral Health Science. 2009: Springer Japan; 2010:403-405.

13. Vaes G. Cellular biology and biochemical mechanism of bone resorption. A review of recent developments on the formation, activation, and mode of action of osteoclasts. Clin Orthop Relat Res. 1988;231: 239-271.

14. Teti A, Zallone A. Do osteocytes contribute to bone mineral homeostasis? Osteocytic osteolysis revisited. Bone. 2009;44(1):11-16.

15. Heino TJ, Hentunen TA, Vaananen HK. Osteocytes inhibit osteoclastic bone resorption through transforming growth factor-beta: enhancement by estrogen. J Cell Biochem. 2002;85(1):185-197.

16. Taylor AF, Saunders MM, Shingle DL, Cimbala JM, Zhou Z, Donahue HJ. Mechanically stimulated osteocytes regulate osteoblastic activity via gap junctions. Am J Physiol Cell Physiol. 2007;292(1):C545-C552.

17. Chan M, Lu X, Huo B, et al. A trabecular bone explant model of osteocyte-osteoblast co-culture for bone mechanobiology. Cell Mol Bioeng. 2009;2(3):405-415.

18. Ara T, Song L, Shimada H, et al. Interleukin-6 in the bone marrow microenvironment promotes the growth and survival of neuroblastoma cells. Cancer Res. 2009;69(1):329-337.

19. Paule B, Clerc D, Rudant C, et al. Enhanced expression of interleukin-6 in bone and serum of metastatic renal cell carcinoma. Hum Pathol. 1998;29(4):421-424.

20. Thomas RJ, Guise TA, Yin JJ, et al. Breast cancer cells interact with osteoblasts to support osteoclast formation. Endocrinology. 1999; 140(10):4451-4458

21. Coleman RE. Clinical features of metastatic bone disease and risk of skeletal morbidity. Clin Cancer Res. 2006;12(20):6243s-6249s.

22. Coleman RE, Rubens RD. The clinical course of bone metastases from breast cancer. Br J Cancer. 1987;55(1):61-66.
23. DuBois SG, Kalika Y, Lukens JN, et al. Metastatic sites in stage IV and IVS neuroblastoma correlate with age, tumor biology, and survival. J Pediatr Hematol/Oncol. 1999;21(3):181-189.

24. Ricciardi S, de Marinis F. Treatment of bone metastases in lung cancer: the actual role of zoledronic acid. Rev Recent Clin Trials. 2009;4(3): 205-211.

25. Yang M, Jiang P, An Z, et al. Genetically fluorescent melanoma bone and organ metastasis models. Clin Cancer Res. 1999;5(11):3549-3559.

26. Guise TA, Mohammad KS, Clines G, et al. Basic mechanisms responsible for osteolytic and osteoblastic bone metastases. Clin Cancer Res. 2006;12(20 Pt 2):6213s-6216s.

27. Eric AGB, Kristiann MD, Kenneth JP, Charles CC, Thomas JR, Laurie KM. Skeletal metastasis of prostate adenocarcinoma in rats: morphometric analysis and role of parathyroid hormone-related protein. Prostate. 1999;39(3):187-197.

28. Keller ET, Brown J. Prostate cancer bone metastases promote both osteolytic and osteoblastic activity. J Cell Biochem. 2004;91(4): 718-729.

29. Roodman GD. Mechanisms of bone metastasis. N Engl J Med. 2004; 350(16):1655-1664.

30. Coleman RE. Metastatic bone disease: clinical features, pathophysiology and treatment strategies. Cancer Treat Rev. 2001;27(3): 165-176.

31. Taichman RS, Cooper C, Keller ET, Pienta KJ, Taichman NS, McCauley LK. Use of the stromal cell-derived factor-1/CXCR4 pathway in prostate cancer metastasis to bone. 2002;62:1832-1837.

32. Chinni SR, Yamamoto H, Dong Z, Sabbota A, Bonfil RD, Cher ML. CXCL12/CXCR4 transactivates HER2 in lipid rafts of prostate cancer cells and promotes growth of metastatic deposits in bone. Mol Cancer Res. 2008;6(3):446-457.

33. Hinton CV, Avraham S, Avraham HK. Role of the CXCR4/ CXCL12 signaling axis in breast cancer metastasis to the brain. Clin Exp Metastasis. 2010;27(2):97-105.

34. Luker KE, Luker GD. Functions of CXCL12 and CXCR4 in breast cancer. Cancer Lett. 2006;238(1):30-41.

35. Ooi LL, Dunstan CR. CXCL12/CXCR4 axis in tissue targeting and bone destruction in cancer and multiple myeloma. $J$ Bone Miner Res. 2009;24(7):1147-1149.

36. Helbig G, Christopherson KW 2nd, Bhat-Nakshatri P, et al. NF-kappaB promotes breast cancer cell migration and metastasis by inducing the expression of the chemokine receptor CXCR4. J Biol Chem. 2003; 278(24):21631-21638.

37. Hirbe AC, Morgan EA, Weilbaecher KN. The CXCR4/SDF-1 chemokine axis: a potential therapeutic target for bone metastases? Curr Pharm Des. 2010;16(11):1284-1290.

38. Hauschka PV, Mavrakos AE, Iafrati MD, Doleman SE, Klagsbrun M. Growth factors in bone matrix. Isolation of multiple types by affinity chromatography on heparin-sepharose. J Biol Chem. 1986;261(27): 12665-12674.

39. Khan SN, Bostrom MP, Lane JM. Bone growth factors. Orthop Clin North Am. 2000;31(3):375-388.

40. Naugler WE, Karin M. The wolf in sheep's clothing: the role of interleukin-6 in immunity, inflammation and cancer. Trends Mol Med. 2008;14(3):109-119.

41. Naka T, Nishimoto N, Kishimoto T. The paradigm of IL-6: from basic science to medicine. Arthritis Res. 2002;4 Suppl 3:S233-S242.

42. Athanasou NA. Pathology of bone injury. Diagn Histopathol. 2009; 15(9):437-443.

43. Tosato G, Jones KD. Interleukin-1 induces interleukin-6 production in peripheral blood monocytes. Blood. 1990;75(6):1305-1310.

44. Holt I, Davie MW, Braidman IP, Marshall MJ. Prostaglandin E2 stimulates the production of interleukin- 6 by neonatal mouse parietal bones. Bone Miner. 1994;25(1):47-57.

45. Eickelberg O, Pansky A, Mussmann R, et al. Transforming growth factor-beta1 induces interleukin-6 expression via activating protein-1 consisting of JunD homodimers in primary human lung fibroblasts. J Biol Chem. 1999;274(18):12933-12938. 
46. Zhang Y, Broser M, Rom W. Activation of the interleukin 6 gene by Mycobacterium tuberculosis or lipopolysaccharide is mediated by nuclear factors NF IL 6 and NF-kappa B. Proc Natl Acad Sci U S A. 1995;92(8):3632.

47. Libermann TA, Baltimore D. Activation of interleukin-6 gene expression through the NF-kappa B transcription factor. Mol Cell Biol. 1990; 10(5):2327-2334.

48. Fitzgerald DC, Meade KG, McEvoy AN, et al. Tumour necrosis factoralpha (TNF-alpha) increases nuclear factor kappaB (NFkappaB) activity in and interleukin-8 (IL-8) release from bovine mammary epithelial cells. Vet Immunol Immunopathol. 2007;116(1-2):59-68.

49. Domingo-Domenech J, Oliva C, Rovira A, et al. Interleukin 6, a nuclear factor-kappaB target, predicts resistance to docetaxel in hormoneindependent prostate cancer and nuclear factor-kappaB inhibition by PS-1145 enhances docetaxel antitumor activity. Clin Cancer Res. 2006;12(18):5578-5586.

50. Heinrich PC, Behrmann I, Muller-Newen G, Schaper F, Graeve L. Interleukin-6-type cytokine signalling through the gp130/Jak/STAT pathway. Biochem J. 1998;334 (Pt 2):297-314.

51. Murakami M, Hibi M, Nakagawa N, et al. IL-6-induced homodimerization of gp130 and associated activation of a tyrosine kinase. Science. 1993;260(5115):1808-1810.

52. Wegiel B, Bjartell A, Culig Z, Persson JL. Interleukin-6 activates PI3K/ Akt pathway and regulates cyclin A1 to promote prostate cancer cell survival. Int J Cancer. 2008;122(7):1521-1529.

53. Hashizume M, Hayakawa N, Mihara M. IL-6 trans-signalling directly induces RANKL on fibroblast-like synovial cells and is involved in RANKL induction by TNF-alpha and IL-17. Rheumatology (Oxford). 2008;47(11):1635-1640

54. O’Brien CA, Gubrij I, Lin SC, Saylors RL, Manolagas SC. STAT3 activation in stromal/osteoblastic cells is required for induction of the receptor activator of NF-kappaB ligand and stimulation of osteoclastogenesis by gp130-utilizing cytokines or interleukin-1 but not 1,25-dihydroxyvitamin D3 or parathyroid hormone. J Biol Chem. 1999;274(27):19301-19308.

55. Wong PK, Quinn JM, Sims NA, van Nieuwenhuijze A, Campbell IK, Wicks IP. Interleukin-6 modulates production of T lymphocyte-derived cytokines in antigen-induced arthritis and drives inflammation-induced osteoclastogenesis. Arthritis Rheum. 2006;54(1):158-168.

56. McGeachy MJ, Bak-Jensen KS, Chen Y, et al. TGF-beta and IL-6 drive the production of IL-17 and IL-10 by T cells and restrain T(H)-17 cellmediated pathology. Nat Immunol. 2007;8(12):1390-1397.

57. Wang L, Yi T, Kortylewski M, Pardoll DM, Zeng D, Yu H. IL-17 can promote tumor growth through an IL-6-Stat3 signaling pathway. $J$ Exp Med. 2009;206(7):1457-1464.

58. Moonga BS, Adebanjo OA, Wang HJ, et al. Differential effects of interleukin-6 receptor activation on intracellular signaling and bone resorption by isolated rat osteoclasts. J Endocrinol. 2002;173(3):395-405.

59. Gambacciani M, Vacca F. Postmenopausal osteoporosis and hormone replacement therapy. Minerva Med. 2004;95(6):507-520.

60. Kanda N, Watanabe S. 17beta-estradiol, progesterone, and dihydrotestosterone suppress the growth of human melanoma by inhibiting interleukin-8 production. J Invest Dermatol. 2001;117(2):274-283.

61. Kramer PR, Kramer SF, Guan G. 17 beta-estradiol regulates cytokine release through modulation of CD16 expression in monocytes and monocyte-derived macrophages. Arthritis Rheum. 2004;50(6) 1967-1975.

62. Bendre MS, Montague DC, Peery T, Akel NS, Gaddy D, Suva LJ. Interleukin-8 stimulation of osteoclastogenesis and bone resorption is a mechanism for the increased osteolysis of metastatic bone disease. Bone. 2003;33(1):28-37.

63. Manna SK, Ramesh GT. Interleukin-8 induces nuclear transcription factor-kappaB through a TRAF6-dependent pathway. J Biol Chem. 2005;280(8):7010-7021

64. Novotny NM, Markel TA, Crisostomo PR, Meldrum DR. Differential IL-6 and VEGF secretion in adult and neonatal mesenchymal stem cells: role of NFkB. Cytokine. 2008;43(2):215-219.
65. Lesmeister MJ, Jorgenson RL, Young SL, Misfeldt ML. 17Beta-estradiol suppresses TLR3-induced cytokine and chemokine production in endometrial epithelial cells. Reprod Biol Endocrinol. 2005;3:74.

66. Bhat-Nakshatri P, Newton TR, Goulet R Jr, Nakshatri H. NF-kappaB activation and interleukin 6 production in fibroblasts by estrogen receptor-negative breast cancer cell-derived interleukin 1alpha. Proc Natl Acad Sci U S A. 1998;95(12):6971-6976.

67. Wang LH, Yang XY, Mihalic K, Xiao W, Li D, Farrar WL. Activation of estrogen receptor blocks interleukin-6-inducible cell growth of human multiple myeloma involving molecular cross-talk between estrogen receptor and STAT3 mediated by co-regulator PIAS3. J Biol Chem. 2001;276(34):31839-31844.

68. Coletta RD, Reynolds MA, Martelli-Junior H, Graner E, Almeida OP, Sauk JJ. Testosterone stimulates proliferation and inhibits interleukin-6 production of normal and hereditary gingival fibromatosis fibroblasts. Oral Microbiol Immunol. 2002;17(3):186-192.

69. Tuck SP, Francis RM. Testosterone, bone and osteoporosis. Front Horm Res. 2009;37:123-132.

70. Papadopoulos AD, Wardlaw SL. Testosterone suppresses the response of the hypothalamic-pituitary-adrenal axis to interleukin-6. Neuroimmunomodulation. 2000;8(1):39-44.

71. Hershman D, Narayanan R. Prevention and management of osteoporosis in women with breast cancer and men with prostate cancer. Curr Oncol Rep. 2004;6(4):277-284.

72. Barille S, Collette M, Bataille R, Amiot M. Myeloma cells upregulate interleukin-6 secretion in osteoblastic cells through cell-to-cell contact but downregulate osteocalcin. Blood. 1995;86(8):3151-3159.

73. Blouin S, Basle MF, Chappard D. Interactions between microenvironment and cancer cells in two animal models of bone metastasis. Br J Cancer. 2008;98(4):809-815.

74. Voorzanger-Rousselot N, Goehrig D, Journe F, et al. Increased Dickkopf-1 expression in breast cancer bone metastases. Br J Cancer. 2007;97(7):964-970.

75. Deyama Y, Tei K, Yoshimura Y, et al. Oral squamous cell carcinomas stimulate osteoclast differentiation. Oncol Rep. 2008;20(3):663-668.

76. Kinder M, Chislock E, Bussard KM, Shuman L, Mastro AM. Metastatic breast cancer induces an osteoblast inflammatory response. Exp Cell Res. 2008;314(1):173-183.

77. Chen YC, Sosnoski DM, Gandhi UH, Novinger LJ, Prabhu KS, Mastro AM. Selenium modifies the osteoblast inflammatory stress response to bone metastatic breast cancer. Carcinogenesis. 2009;30(11): 1941-1948.

78. Mizutani K, Sud S, Pienta KJ. Prostate cancer promotes CD11b positive cells to differentiate into osteoclasts. J Cell Biochem. 2009;106(4): $563-569$.

79. Kudo O, Sabokbar A, Pocock A, Itonaga I, Fujikawa Y, Athanasou NA Interleukin-6 and interleukin-11 support human osteoclast formation by a RANKL-independent mechanism. Bone. 2003;32(1):1-7.

80. Schwarz EM, Ritchlin CT. Clinical development of anti-RANKL therapy. Arthritis Res Ther. 2007;9 Suppl 1:S7.

81. Lee KM, Kang BS, Lee HL, et al. Spinal NF-kB activation induces COX-2 upregulation and contributes to inflammatory pain hypersensitivity. Eur J Neurosci. 2004;19(12):3375-3381.

82. Kaji H, Sugimoto T, Kanatani M, Fukase M, Kumegawa M, Chihara K. Prostaglandin E2 stimulates osteoclast-like cell formation and boneresorbing activity via osteoblasts: role of cAMP-dependent protein kinase. J Bone Miner Res. 1996;11(1):62-71.

83. Kurihara N, Bertolini D, Suda T, Akiyama Y, Roodman GD. IL-6 stimulates osteoclast-like multinucleated cell formation in long term human marrow cultures by inducing IL-1 release. J Immunol. 1990;144(11): 4226-4230.

84. Renard P, Zachary MD, Bougelet C, et al. Effects of antioxidant enzyme modulations on interleukin-1-induced nuclear factor kappa B activation. Biochem Pharmacol. 1997;53(2):149-160.

85. Soerjomataram I, Louwman MW, Ribot JG, Roukema JA, Coebergh JW. An overview of prognostic factors for long-term survivors of breast cancer. Breast Cancer Res Treat. 2008;107(3):309-330. 
86. Lilja H, Ulmert D, Vickers AJ. Prostate-specific antigen and prostate cancer: prediction, detection and monitoring. Nat Rev Cancer. 2008; 8(4):268-278.

87. Harris L, Fritsche H, Mennel R, et al. American Society of Clinical Oncology 2007 update of recommendations for the use of tumor markers in breast cancer. J Clin Oncol. 2007;25(33):5287-5312.

88. Culig Z, Hobisch A. Role of IL-6 in regulating the androgen receptor. Androgen Action in Prostate Cancer. 2009:451-463.

89. Knüpfer H, Preiß R. Significance of interleukin-6 (IL-6) in breast cancer (review). Breast Cancer Res Treat. 2007;102(2):129-135.

90. Kuroda K, Nakashima J, Kanao K, et al. Interleukin 6 is associated with cachexia in patients with prostate cancer. Urology. 2007; 69(1):113-117.

91. Tumminello FM, Badalamenti G, Incorvaia L, Fulfaro F, D'Amico C, Leto G. Serum interleukin-6 in patients with metastatic bone disease: correlation with cystatin C. Med Oncol. 2008;26(1):10-15.

92. George DJ, Halabi S, Shepard TF, et al. The prognostic significance of plasma interleukin-6 levels in patients with metastatic hormonerefractory prostate cancer: results from cancer and leukemia group B 9480. Clin Cancer Res. 2005;11(5):1815-1820.

93. Ahmed OI, Adel AM, Diab DR, Gobran NS. Prognostic value of serum level of interleukin- 6 and interleukin- 8 in metastatic breast cancer patients. Egypt J Immunol. 2006;13(2):61-68.

94. Roberto S, Sara J, Ina B, et al. Circulating interleukin-6 predicts survival in patients with metastatic breast cancer. Int J Cancer. 2003; 103(5):642-646.

95. Shariat SF, Andrews B, Kattan MW, Kim J, Wheeler TM, Slawin KM. Plasma levels of interleukin-6 and its soluble receptor are associated with prostate cancer progression and metastasis. Urology. 2001; 58(6):1008-1015.

96. Shariat SF, Kattan MW, Traxel E, et al. Association of pre- and postoperative plasma levels of transforming growth factor beta(1) and interleukin 6 and its soluble receptor with prostate cancer progression. Clin Cancer Res. 2004;10(6):1992-1999.

97. Strassmann G, Fong M, Kenney JS, Jacob CO. Evidence for the involvement of interleukin 6 in experimental cancer cachexia. J Clin Invest. 1992;89(5):1681-1684.

98. Twillie DA, Eisenberger MA, Carducci MA, Hseih WS, Kim WY, Simons JW. Interleukin-6: a candidate mediator of human prostate cancer morbidity. Urology. 1995;45(3):542-549.

99. Iwase S, Murakami T, Saito Y, Nakagawa K. Steep elevation of blood interleukin-6 (IL-6) associated only with late stages of cachexia in cancer patients. Eur Cytokine Netw. 2004;15(4):312-316.

100. Kang SH, Kim JI, Moon HS, et al. Overt bone marrow metastasis from early gastric cancer. Endoscopy. 2008;40 Suppl 2: E34-E35.

101. Sudo H, Takagi Y, Katayanagi S, et al. Bone metastasis of gastric cancer. Gan To Kagaku Ryoho. 2006;33(8):1058-1060.

102. Ashizawa T, Okada R, Suzuki Y, et al. Clinical significance of interleukin-6 (IL-6) in the spread of gastric cancer: role of IL-6 as a prognostic factor. Gastric Cancer. 2005;8(2):124-131.

103. Nakchbandi IA, Mitnick MA, Lang R, Gundberg C, Kinder B, Insogna K. Circulating levels of interleukin-6 soluble receptor predict rates of bone loss in patients with primary hyperparathyroidism. J Clin Endocrinol Metab. 2002;87(11):4946-4951.

104. Chalaris A, Garbers C, Rabe B, Rose-John S, Scheller J. The soluble interleukin 6 receptor: generation and role in inflammation and cancer. Eur J Cell Biol. Epub 2010 Dec 7.

105. Rose-John S, Neurath MF. IL-6 trans-signaling: the heat is on. Immunity. 2004;20(1):2-4.

106. Atreya R, Neurath MF. Signaling molecules: the pathogenic role of the IL-6/STAT-3 trans signaling pathway in intestinal inflammation and in colonic cancer. Curr Drug Targets. 2008;9(5): 369-374.

107. Knupfer H, Preiss R. Lack of knowledge: breast cancer and the soluble interleukin-6 receptor. Breast Care (Basel). 2010;5(3):177-180.
108. Santer FR, Malinowska K, Culig Z, Cavarretta IT. Interleukin-6 trans-signalling differentially regulates proliferation, migration, adhesion and maspin expression in human prostate cancer cells. Endocr Relat Cancer. 2009;17(1):241-253.

109. Woods Ignatoski KM, Friedman J, Escara-Wilke J, et al. Change in markers of bone metabolism with chemotherapy for advanced prostate cancer: interleukin-6 response is a potential early indicator of response to therapy. J Interferon Cytokine Res. 2008;29(2):105-112.

110. Wang TH, Chan YH, Chen CW, et al. Paclitaxel (Taxol) upregulates expression of functional interleukin- 6 in human ovarian cancer cells through multiple signaling pathways. Oncogene. 2006;25(35): 4857-4866.

111. Stark JR, Li H, Kraft P, et al. Circulating prediagnostic interleukin-6 and $\mathrm{C}$-reactive protein and prostate cancer incidence and mortality. Int J Cancer. 2009;124(11):2683-2689.

112. Pinski JK, Goldman B, Dorff T, et al. SWOG S0354: a phase II trial of CNTO328, a monoclonal antibody against interleukin-6 (IL-6), in chemotherapy pretreated patients (pts) with castration-resistant prostate cancer (CRPC). J Clin Oncol. 2009;27(15S):5143.

113. Luqmani YA. Mechanisms of drug resistance in cancer chemotherapy. Med Princ Pract. 2005;14 Suppl 1:35-48.

114. Wilson TR, Johnston PG, Longley DB. Anti-apoptotic mechanisms of drug resistance in cancer. Curr Cancer Drug Targets. 2009; 9(3):307-319.

115. Rincon M, Broadwater G, Harris L, et al. Interleukin-6, multidrug resistance protein-1 expression and response to paclitaxel in women with metastatic breast cancer: results of cancer and leukemia group B trial 159806. Breast Cancer Res Treat. 2006;100(3): 301-308.

116. Chung TD, Yu JJ, Kong TA, Spiotto MT, Lin JM. Interleukin-6 activates phosphatidylinositol-3 kinase, which inhibits apoptosis in human prostate cancer cell lines. Prostate. 2000;42(1):1-7.

117. Garcia-Tunon I, Ricote M, Ruiz A, Fraile B, Paniagua R, Royuela M. IL-6, its receptors and its relationship with bcl-2 and bax proteins in infiltrating and in situ human breast carcinoma. Histopathology. 2005;47(1):82-89.

118. Petrut B, Trinkaus M, Simmons C, Clemons M. A primer of bone metastases management in breast cancer patients. Curr Oncol. 2008; 15(Suppl 1):S50-S57.

119. Coleman RE. Management of bone metastases. Oncologist. 2000; 5(6):463-470.

120. Melton L, Coombs A. Actemra poised to launch IL-6 inhibitors. Nat Biotechnol. 2008;26(9):957-959.

121. Kudo M, Jono H, Shinriki S, et al. Antitumor effect of humanized anti-interleukin-6 receptor antibody (tocilizumab) on glioma cell proliferation. J Neurosurg. 2009;111(2):219-225.

122. Yoshio-Hoshino N, Adachi Y, Aoki C, Pereboev A, Curiel DT, Nishimoto N. Establishment of a new interleukin-6 (IL-6) receptor inhibitor applicable to the gene therapy for IL-6-dependent tumor. Cancer Res. 2007;67(3):871-875.

123. Fonseca JESM, Canhão H, Choy E. Interleukin-6 as a key player in systemic inflammation and joint destruction. Autoimmun Rev. 2009; 8(7):538-542.

124. Li J, Hu XF, Xing PX. CNTO-328 (Centocor). Curr Opin Investig Drugs. 2005;6(6):639-645.

125. Puchalski T, Prabhakar U, Jiao Q, Berns B, Davis HM. Pharmacokinetic and pharmacodynamic modeling of an anti-interleukin-6 chimeric monoclonal antibody (siltuximab) in patients with metastatic renal cell carcinoma. Clin Cancer Res. 2010;16(5):1652-1661.

126. Rossi JF, Negrier S, James ND, et al. A Phase I/II study of siltuximab (CNTO 328), an anti-interleukin-6 monoclonal antibody, in metastatic renal cell cancer. Br J Cancer. 2010;103(8):1154-1162.

127. Voorhees PM, Manges RF, Somlo G, et al. A phase II multicenter study of CNTO 328, an anti-IL-6 monoclonal antibody, in patients (pts) with relapsed or refractory multiple myeloma (MM). J Clin Oncol (Meeting Abstracts). 2009;27(15S):8527. 
128. Zaki MH, Nemeth JA, Trikha M. CNTO 328, a monoclonal antibody to IL-6, inhibits human tumor-induced cachexia in nude mice. Int $J$ Cancer. 2004;111(4):592-595.

129. Wallner L, Dai J, Escara-Wilke J, et al. Inhibition of interleukin-6 with CNTO328, an anti-interleukin-6 monoclonal antibody, inhibits conversion of androgen-dependent prostate cancer to an androgenindependent phenotype in orchiectomized mice. Cancer Res. 2006; 66(6):3087-3095.

130. Karkera J, Steiner H, Li W, et al. The anti-interleukin-6 antibody siltuximab down-regulates genes implicated in tumorigenesis in prostate cancer patients from a Phase I study. Prostate. Epub 2011 Feb 14.

131. DorffTB, Goldman B, Pinski JK, et al. Clinical and correlative results of SWOG S0354: a Phase II trial of CNTO328 (Siltuximab), a monoclonal antibody against interleukin-6, in chemotherapy-pretreated patients with castration-resistant prostate cancer. Clin Cancer Res. 2010;16(11):3028-3034.

132. Sheridan C. Pharma consolidates its grip on post-antibody landscape. Nat Biotechnol. 2007;25(4):365-366.
133. Silverman J, Liu Q, Bakker A, et al. Multivalent avimer proteins evolved by exon shuffling of a family of human receptor domains. Nat Biotechnol. 2005;23(12):1556-1561.

134. Braddock M. 11th annual inflammatory and immune diseases drug discovery and development summit. Expert Opin Investig Drugs. 2007;16:909-917.

135. Brandt SJ, Bodine DM, Dunbar CE, Nienhuis AW. Dysregulated interleukin 6 expression produces a syndrome resembling Castleman's disease in mice. J Clin Invest. 1990;86(2):592-599.

136. Wurch T, Lowe P, Caussanel V, Bes C, Beck A, Corvaia N. Development of novel protein scaffolds as alternatives to whole antibodies for imaging and therapy: status on discovery research and clinical validation. Curr Pharm Biotechnol. 2008;9:502-509.

137. Gebauer M, Skerra A. Engineered protein scaffolds as next-generation antibody therapeutics. Curr Opin Chem Biol. 2009;13(3):245-255.

Cancer Management and Research

\section{Publish your work in this journal}

Cancer Management and Research is an international, peer-reviewed open access journal focusing on cancer research and the optimal use of preventative and integrated treatment interventions to achieve improved outcomes, enhanced survival and quality of life for the cancer patient The journal welcomes original research, clinical \& epidemiological
Dovepress

studies, reviews \& evaluations, guidelines, expert opinion \& commentary, case reports \& extended reports. The manuscript management system is completely online and includes a very quick and fair peerreview system, which is all easy to use. Visit http://www.dovepress.com/ testimonials.php to read real quotes from published authors.

Submit your manuscript here: http://www.dovepress.com/cancer-management-and-research-journal 